\title{
Cathepsin B defines leader cells during the collective invasion of salivary adenoid cystic carcinoma
}

\author{
JIA-SHUN WU ${ }^{1}$, ZHU-FENG LI $^{1}$, HAO-FAN WANG ${ }^{1}$, XIANG-HUA YU $^{1}$, XIN PANG $^{1}$, \\ JING-BIAO WU ${ }^{1}$, SHA-SHA WANG ${ }^{1}$, MEI ZHANG ${ }^{1}$, XIAO YANG $^{1}$, MING-XIN CAO $^{1}$, \\ YA-JIE TANG ${ }^{2}$, XIN-HUA LIANG ${ }^{1}$, MIN ZHENG $^{3}$ and YA-LING TANG ${ }^{1}$
}

\begin{abstract}
${ }^{1}$ State Key Laboratory of Oral Diseases and National Clinical Research Center for Oral Diseases, West China Hospital of Stomatology (Sichuan University), Chengdu, Sichuan 610041; ${ }^{2}$ Key Laboratory of Fermentation

Engineering (Ministry of Education), Hubei Provincial Cooperative Innovation Center of Industrial Fermentation, Hubei Key Laboratory of Industrial Microbiology, Hubei University of Technology, Wuhan, Hubei 430068; ${ }^{3}$ Department of Stomatology, Zhoushan Hospital, Wenzhou Medical University, Zhoushan, Zhejiang 316021, P.R. China
\end{abstract}

Received October 16, 2018; Accepted February 11, 2019

DOI: 10.3892/ijo.2019.4722

\begin{abstract}
Cathepsin B (CTSB) has been reported to be involved in cancer metastasis by altering extracellular matrix (ECM) remodeling and facilitating invasion. However, the contribution of CTSB to collective cell invasion in salivary adenoid cystic carcinoma (SACC) and the underlying mechanisms remain unclear. The present study demonstrated that collective cell invasion is commonly observed in SACC without a complete epithelial-mesenchymal transition signature. CTSB was found to be overexpressed in the invasive front of SACC compared to the tumor center, and was associated with a poor prognosis of patients with SACC. Subsequently, a 3D spheroid invasion assay was established in order to recapitulate the collective cell invasion of SACC and the results revealed that CTSB was only
\end{abstract}

Correspondence to: Professor Ya-Ling Tang, State Key Laboratory of Oral Diseases and National Clinical Research Center for Oral Diseases, West China Hospital of Stomatology (Sichuan University), No. 14, Section 3, Renminnan Road, Chengdu, Sichuan 610041, P.R. China

E-mail: tangyaling@scu.edu.cn

Professor Min Zheng, Department of Stomatology, Zhoushan Hospital, Wenzhou Medical University, 739 Dingshen Road, Lincheng Street, Zhoushan, Zhejiang 316021, P.R. China

E-mail: zm_iblue610@sina.com

Abbreviations: CTSB, cathepsin B; ECM, extracellular matrix; EMT, epithelial-mesenchymal transition; FAK, focal adhesion kinase; GFP, green fluorescent protein; PNI, perineural invasion; SACC, salivary adenoid cystic carcinoma; SNK, Student-Newman-Keuls; IHC, immunohistochemistry; MMP, matrix metalloproteinase; SEM, scanning electron microscopy; TNM, tumor-node-metastasis; uPA, uridylyl phosphate adenosine

Key words: extracellular matrix remodeling, invasion front, partial epithelial-mesenchymal transition, 3D culture expressed in leader cells. The knockdown of CTSB by siRNA inhibited the migration and invasion of SACC-83 cells and impaired the formation of leader cells. CTSB knockdown also disrupted cytoskeletal organization, altered cell morphology and inhibited ECM remodeling by downregulating matrix metalloproteinase-9, focal adhesion kinase and Rho/ROCK function. Therefore, the present study provides evidence that CTSB may define leader cells in SACC and is required for collective cell invasion as a potential key regulator of ECM remodeling.

\section{Introduction}

Metastasis, one of the hallmarks of cancer, is the leading cause of mortality in patients with cancer (1). The first step of metastasis is the invasion of cancer cells into the basement membrane and extracellular matrix (ECM) (2). It has been widely accepted that during the invasion process, cancer cells require epithelial-mesenchymal transition (EMT) for acquisition of mesenchymal phenotypes and in order to invade (3). During EMT, tumor cells lose their intercellular adhesion and detach from the primary tumor mass. Subsequently, the cells invade into the ECM and further metastasize to distant organs as single cells $(4,5)$. However, increasing evidence has demonstrated that a number of human cancer cells retain intercellular adhesion and invade as cohesive multicellular groups, which is a phenomenon termed collective cell invasion or migration $(4,6,7)$.

The multicellular units of collective cell invasion are composed of heterogeneous populations of cancer cells that differ in gene expression signatures, as well as in their proliferative, invasive and metastatic abilities (8). Leader cells are the group of cancer cells located in the invasive front of multicellular units, at the interface of the tumor and ECM, whereas follower cells are located in the rear and follow $(9,10)$. Notably, leader cells steer and maintain the migration of a cohesive cell group by exploring the tissue environment, generating traction force and finding or generating the path by 
ECM remodeling $(11,12)$. In order to investigate the roles of heterogeneous populations in collective invasion, an increasing number of molecules have been identified that define leader cells in different types of cancer. In breast cancer, leader cells are defined by basal epithelial genes, such as cytokeratin-14 and p63, whereas senescent tumor cells have been demonstrated to lead collective invasion in thyroid cancer $(13,14)$. Although the collective invasion of cancer cells has been extensively investigated, the contributions of different heterogeneous populations of cancer cells to this process remain unclear.

The degradation of basement membranes and connective tissues by matrix proteases provides the pathways for cancer cell invasion and metastasis $(15,16)$. Previous studies have demonstrated that collective cell invasion requires proteolysis-mediated ECM remodeling to degrade the physical barrier of the ECM and generate the path for invasion, and leader cells play critical roles in ECM remodeling (15). Wolf et al (17) reported that in the collective cell invasion of breast cancer, leader cells selectively realign fibers via matrix metalloproteinase (MMP)-14 on the cell surface and generate tube-like microtracks, which are further enlarged into macrotracks to accommodate cell groups of collective movement. In addition, MMP inhibitors and the knockdown of MMP-14 have been demonstrated to inhibit collective cell invasion and induce collective-to-amoeboid transition (17,18). Cathepsin B (CTSB) is also an important matrix protease that is involved in protein turnover in lysosomes $(19,20)$. The increased expression of CTSB has been reported in numerous types of cancer, including breast, brain and colorectal cancer, and is considered a marker of a poor prognosis (21-23). It has been demonstrated that the overexpression of CTSB in breast cancer cells is an indicator of higher ECM proteolysis and an enhanced collective cell invasion (21). However, the contribution of CTSB to the collective cell invasion of salivary adenoid cystic carcinoma (SACC) and the underlying mechanisms remain unclear.

In the present study, the invasive pattern in human SACC samples was examined and the expression of EMT markers and CTSB in the invasive front of SACC was detected. Collective cell invasion was commonly observed, accompanied by partial EMT, and CTSB was overexpressed in the invasion front of SACC. Subsequently, a 3D spheroid invasion assay was established to recapitulate the collective cell invasion of SACC, and the role of CTSB in collective invasion was investigated. The data demonstrated that CTSB plays an important role in leader cells among migrating SACC cell groups.

\section{Materials and methods}

Histological analysis. A total of 76 SACC specimens were obtained from the Department of Oral Pathology, West China Hospital of Stomatology, Sichuan University (Chengdu, China) between 2007 and 2008. The human tissue samples and clinical data were obtained with written informed consent, and the protocols were approved by the Institutional Ethics Committee of the West China Medical Center, Sichuan University (Chengdu, China; approval no. WCHSIRB-D-2016-176). The collected SACC specimens were fixed with $10 \%$ buffered formalin and embedded in paraffin. The 4- $\mu$ m-thick sections were stained with hematoxylin and eosin for the examination of tumor invasion.
Cell culture and transfection. SACC-83 cells were obtained from the State Key Laboratory of Oral Diseases of Sichuan University (Chengdu, China). The cells were cultured in DMEM high-glucose (HyClone; GE Healthcare Life Sciences, Logan, UT, USA) supplemented with $10 \%$ fetal bovine serum (Gibco/Thermo Fisher Scientific, Inc., Waltham, MA, USA), and maintained in an incubator at $37^{\circ} \mathrm{C}$ and $5 \% \mathrm{CO}_{2}$. A negative control siRNA and two siRNAs against CTSB were purchased from Shanghai Genechem Co., Ltd. (Shanghai, China). The cells were transfected with siRNA (20 pM) using Lipofectamine ${ }^{\circledR} 2000$ reagent (Invitrogen/Thermo Fisher Scientific, Inc.) according to the manufacturer's instructions. The sequences of the primers were as follows: Duplex-1, GCC UCUAUGA AUCCCAUGUTTACAUGGGAUUCAUAG AGGCTT; duplex-2, GUCCCACCAUCAAAGAGAUTT AUCUCUUUGAUGGUGGGACTT; duplex-3, GUGGAA UCGAAUCAGAAGUTTACUUCUGAUUCGAUUCCA CTT; and control, UUCUCCGAACGUGUCACGUTTACG UGACACGUUCGGAGAATT. The transfected cells were subjected to reverse transcription-quantitative polymerase chain reaction ( $\mathrm{RT}$-qPCR), western blot analysis, immunofluorescence staining, migration and invasion assays, and 3D spheroid culture at $48 \mathrm{~h}$ following transfection. To label the SACC-83 cells, cDNA encoding mCherry or GFP (Shanghai Genechem Co., Ltd, Shanghai, China) was cloned into the Ubi-MCS-SV40-Cherry-IRES-puro vector or Ubi-MCS-SV40-GFP-IRES-puro vector (Shanghai Genechem Co., Ltd., Shanghai, China). The SACC-83 cells were infected with the virus and subsequently selected with puromycin.

Immunohistochemistry (IHC). The 4- $\mu$ m-thick sections of SACC were deparaffinized and then rehydrated in a graded ethanol series to distilled water. The sections were autoclaved for antigen retrieval and blocked with $3 \%$ hydrogen peroxide and goat serum albumin, followed by routine immunohistochemical staining procedures, as previously described $(24,25)$. The primary antibodies used were as follows: Rabbit anti-E-cadherin, 1:200 (cat. no. UM870076; OriGene Technologies, Inc., Shanghai, China); mouse anti-N-cadherin, 1:200 (cat. no. UM500023; OriGene Technologies, Inc.); rabbit anti-vimentin, 1:200 (cat. no. UM800054CF; OriGene Technologies, Inc.); and rabbit anti-CTSB, 1:50 (cat. no. ab230401; Abcam, Cambridge, MA, USA).

Within each tumor, the cancer cells that were closest to the connective tissue or other normal tissue (such as the salivary glands and nerves) were defined as the invasive tumor front and the other tumor areas were regarded as the central tumor areas (26). The immunohistochemical staining was scored by two independent researchers (JSW and SSW), and the invasive front and central tumor areas were scored separately. The intensity of immunostaining was scored as follows: 0 , no staining; 1, mild staining; 2, moderate staining; and 3, strong staining. The percentages of stained cells were recorded as follows: 0 , negative; $1,0-10 \%$ positive; $2,10-50 \%$ positive; or 3 , $>50 \%$ positive. The $\mathrm{H}$ score was then calculated by multiplying the two variables and the result was categorized as negative $(0-4)$ or positive (>4) expression.

$R T$ - $q P C R$. Total RNA was extracted using an RNeasy Mini kit (Qiagen Co.Ltd., Shanghai, China CA,) and reverse transcribed 
into cDNA using the High-Capacity cDNA Reverse Transcription kit (Applied Biosystems/Thermo Fisher Scientific, Inc.). The primer sequences used were as follows: CTSB forward, 5'-CACTGACTGGGGTGACAATG-3' and reverse, 5'-GCCACCACTTCTGATTCGAT-3'; $\beta$-actin forward, 5'-GGCCTCCAA GGAGTAAGACC-3' and reverse, 5'-AGGGGTCTACATGGCAACTG-3'; ROCK1 forward, 5'-CGAAGATGCCATGTTAAGTGC-3' and reverse, 5'-ATC TTGTAGAAAGCGTTCGAG-3'; ROCK2 forward, 5'-CAA CTGTGAGGCTTGTATGAAG-3' and reverse, 5'-TGCAAG GTGCTATAATCTCCTC-3'; RhoA forward, 5'-TATCGA GGTGGATGGAAAGC-3' and reverse, 5'-TCTGGGGTCCA CTTTTCTG-3'; and MMP-9 forward, 5'-CAACTGTCCCTG CCCGAGA-3' and reverse, 5'-CAAAGGCGTCGTCAATCA CC-3'. The PCR reactions were performed using SYBR-Green (Roche Diagnostics, Indianapolis, IN, USA) based on the following protocol: Preincubation at $94^{\circ} \mathrm{C}$ for $10 \mathrm{~min}$, followed by 45 cycles of $15 \mathrm{sec}$ at $95^{\circ} \mathrm{C}, 30 \mathrm{sec}$ at $60^{\circ} \mathrm{C}$, and $30 \mathrm{sec}$ at $72^{\circ} \mathrm{C}$. The sample values were normalized to the housekeeping gene, $\beta$-actin.

Western blot analysis. The protein samples were harvested using a total protein lysates kit (cat no. KGP250; Nanjing KeyGen Biotech Co. Ltd., Nanjing, China). The protein concentrations were determined using the BCA Protein Assay kit (Santa Cruz Biotechnology, Inc., Dallas, TX, USA) according to the manufacturer's instructions. A total of $25 \mu \mathrm{g}$ protein from each sample was subjected to SDS-polyacrylamide gel electrophoresis (gel, 10\%; Bio-Rad Laboratories, Inc., Hercules, CA, USA) and transferred to a PVDF membrane (Immobilon; EMD Millipore, Bedford, MA, USA). Immunoprobing was performed by incubating the membrane with anti-GAPDH antibody $(1: 1,000$; cat. no. 5174; Cell Signaling Technology, Inc., Danvers, MA, USA), anti-CTSB antibody (1:1,000; cat. no. ab230401, Abcam), anti-FAK antibody (1:1,000; cat. no. WL01696; Wanleibio Co., Ltd., Shanghai, China) and anti-MMP-9 antibody (1:1,000; cat. no. 10375-2-AP; Proteintech Group, Inc., Chicago, IL, USA) overnight at $4^{\circ} \mathrm{C}$, followed by binding with a HRP-conjugated secondary antibody (1:2,000; cat. no. 7074; Cell Signaling Technology, Inc.) for $1 \mathrm{~h}$ at room temperature. The Pierce ECL Western Blotting Substrate (Thermo Fisher Scientific, Inc.) was used for detection.

Immunofluorescence staining. The cells cultured in 3D gel were fixed with $4 \%$ formaldehyde for $20 \mathrm{~min}$. After washing with PBS for $10 \mathrm{~min}$, the cells were permeabilized with $0.2 \%$ Triton X-100 for $30 \mathrm{~min}$. The cells were then blocked with $1 \%$ bovine serum albumin in PBS for $30 \mathrm{~min}$. F-actin was stained with Rhodamine phalloidin (1:400; Invitrogen Molecular Probes/Thermo Fisher Scientific, Inc.) for $25 \mathrm{~min}$ in order to visualize the cell cytoskeleton. The cells were incubated with primary antibodies against E-cadherin (1:400; cat. no. 20874-1-AP; Proteintech Group, Inc.) and CTSB (1:50; cat. no. ab230401; Abcam) at $4^{\circ} \mathrm{C}$ overnight. After washing with PBS, the cells were incubated with TRITC goat anti-rabbit IgG (1:100; catalog no. ZF-0316; ZSGB-Bio, Inc., Beijing, China) for $1 \mathrm{~h}$ at room temperature, and the nuclei were stained DAPI. Fluorescence was observed using a confocal laser microscope (Olympus FluoView FV1000; Olympus Corp., Tokyo, Japan).
Migration and invasion assays. The cells were seeded in 6 -well plates at a density of $1.5 \times 10^{5}$ cell $/ \mathrm{ml}$. After $24 \mathrm{~h}$, the cells were cultured in serum-free medium, and wounds were created by scraping each plate with a $200-\mu 1$ pipette tip. Images of identical regions of the scratch were captured at various time points using a phase contrast microscope (Olympus IX 71; Olympus Corp., Tokyo, Japan). Matrigel invasion assays were performed in Transwell chambers $(8-\mu \mathrm{m}$ pore size; Costar; Corning Inc., NY, USA) coated with $100 \mu \mathrm{l}$

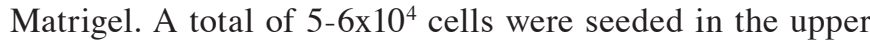
compartment in $200 \mathrm{ml}$ serum-free medium and the chambers were then placed in 24-well dishes containing $700 \mu \mathrm{l}$ DMEM with $10 \%$ FBS. After 24 or 48 h, the membranes were fixed with $4 \%$ formaldehyde and stained with $10 \%$ Giemsa staining solution for $30 \mathrm{~min}$ at room temperature. After removing the cells on the upper surface of the membrane, the cells on the lower membrane surface were counted under a microscope (Olympus IX 71; Olympus Corp.).

$3 D$ spheroid culture. Multicellular spheroids were generated using the hanging drop technique or by plating the cells on 96-well ultra-low attachment plates (Corning, Inc., NY, USA) or soft agar-coated 96-well plates. For the hanging drop method, the cells were re-suspended in DMEM growth medium supplemented with $10 \%$ methylcellulose at a density of $5 \times 10^{4}$ cells $/ \mathrm{ml}$, and incubated in $25 \mu 1$ droplets overnight as previously described (27). For the latter method, $1 \%$ agar was used to coat 96 -well plates. The cells were re-suspended in $200 \mu \mathrm{l}$ DMEM growth medium at a density of $5 \times 10^{4}$ cells $/ \mathrm{ml}$ and seeded in 96-well ultra-low attachment plates or soft agar-coated 96-well plates. The cells were cultured for 48-72 h to ensure multicellular aggregation. Following cell aggregation, the spheroids were incorporated into non-pepsinized rat tail collagen solution (BD Biosciences, San Jose, CA, USA) prior to collagen polymerization. Subsequently, DMEM growth medium was added and the plates were incubated at $37^{\circ} \mathrm{C}$ for $24-48 \mathrm{~h}$. The definition of leader cells was based on their positions in the cell cluster, with the leader and follower cells located at the front and the back of the cluster, respectively (10). Therefore, protrusive cells at the front of the invasive strands were identified as leader cells. To determine whether CTSB was required for leader cell formation, mixed spheroid culture was performed by co-culturing the control untreated GFP-expressing cells with siCTSB-transfected mCherry-expressing cells, or by co-culturing control mCherry-expressing cells with siCTSB-transfected GFP-expressing cells. A confocal laser microscope (Olympus FluoView FV1000; Olympus Corp.) was used to observe the tumor organoids and assess the incidence of GFP- or mCherry-expressing cells leading collective invasion strands according to the following formula: 100x (number of GFP- or mCherry-expressing leader cells/total number of leader cells). In order to assess force-mediated ECM remodeling, $2.5 \times 10^{4}$ cells were mixed with $1 \mathrm{ml}$ collagen I and Matrigel mixture, and the gel mix was plated in a 96-well plate at a density of $100 \mu$ l per well as described previously (28). After 4 days, the plates were scanned, and the relative diameter of the well and the gel were measured using ImageJ (National Institutes of Health, Bethesda, MD, USA). The extent of contraction was assessed 
A

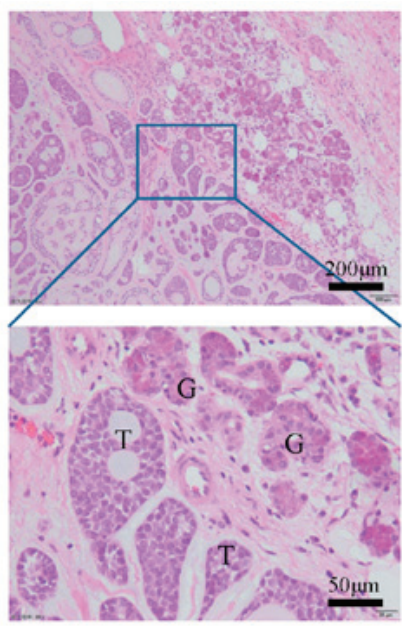

B

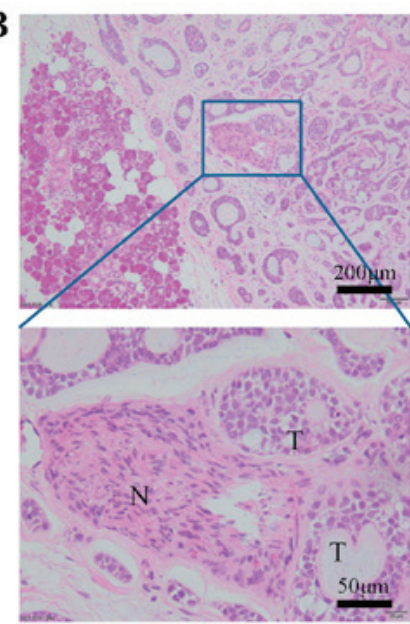

C

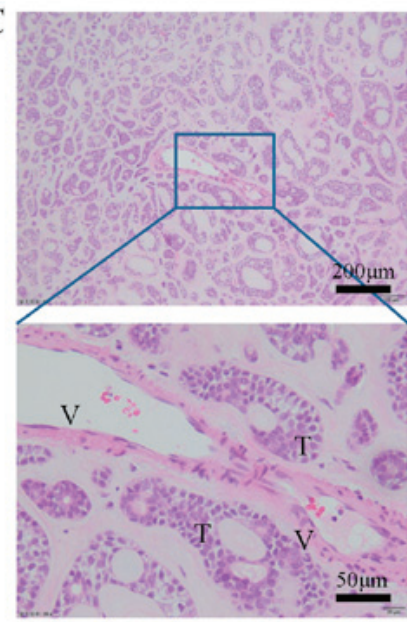

Figure 1. Collective cell invasion is the main invasion mode of SACC. The 4- $\mu \mathrm{m}$-thick sections of SACC were stained with hematoxylin and eosin. The tumor cells had invaded into the adjacent (A) gland, (B) nerve and (C) vessel tissue as tightly connected multicellular units. The top panels and the bottom panels were captured at x100 magnification and x400 magnification, respectively. SACC, salivary adenoid cystic carcinoma; T, tumor cells; G, adjacent gland; N, nerve; $\mathrm{V}$, vessel tissue.

using the following formula: 100x (well diameter - gel diameter)/well diameter.

Scanning electron microscopy (SEM). The samples were fixed with $4 \%$ glutaraldehyde for $15 \mathrm{~min}$ at room temperature, and after washing with PBS, the samples were dehydrated with serially increasing concentrations of ethanol at 30, 40, 50, $60,70,80,90,95,99$ and $100 \%$ for 10 min each. The sample was critical point dried and sputter-coated with gold before examination under a FEI Quanta FEG 250 scanning electron microscope (FEI, Hillsboro, OR, USA).

Statistical analysis. Statistical analyses were performed using the Statistical Package for Social Science software (version 22.0; IBM Corp., Armonk, NY, USA) and GraphPad Prism (version 5.03; GraphPad Software, Inc., La Jolla, CA, USA). The numerical data are expressed as the means \pm standard deviation. The data were analyzed with the Student's t-test (comparisons between 2 groups), or with one-way analysis of variance and Student-Newman-Keuls test (comparisons between $>2$ groups). The association between CTSB expression and the clinicopathological characteristic of the patients with SACC was analyzed using the Chi-square test. Survival analysis was performed using the Kaplan-Meier method, and significant differences were compared using the log-rank test. A value of $\mathrm{P}<0.05$ was considered to indicate a statistically significant difference.

\section{Results}

SACC cells invade as multicellular units without a complete EMT signature. In the SACC invasive regions, the neoplastic epithelial cells invaded into the adjacent gland, nerve and vessel tissue and organized into multicellular units (Fig. 1). The IHC results revealed that the invasion front preserved E-cadherin expression, indicating that tumor cells of SACC invade as collective cell groups (Fig. 2A). To further assess whether the EMT occurs in the invasion border of SACC, the expression of mesenchymal markers was investigated by
IHC. Notably, the results demonstrated that N-cadherin and vimentin were expressed in the entire cancer area of SACC without a loss of expression in the invasive front (Fig. 2A). These data indicated that invasive cancer cells of SACC lack a complete EMT signature.

CTSB is overexpressed at the invasion border and is associated with a poor prognosis of patients with SACC.As CTSB promotes cancer invasion and metastasis, the expression of CTSB was investigated at the invasion border of 76 SACC samples. CTSB staining was present predominantly in the cytoplasm of the SACC cells. Notably, the cytoplasmic immunoreaction for CTSB protein was higher at the invasion border compared to the tumor center (Fig. 2B). The clinicopathological and prognostic implications of the CTSB overexpression status at the invasion border of SACC were subsequently examined. The increased CTSB expression at the invasion border was closely associated with a poor pathological type, nerve invasion, advanced clinical tumor-node-metastasis stage, recurrence and metastasis of SACC (Table I). Kaplan-Meier survival curve analysis also demonstrated that the CTSB level was associated with the overall survival of patients with SACC and that the patients with a low CBST expression level lived longer than those with a high CTSB level ( $\mathrm{P}<0.05$; Fig. $2 \mathrm{C})$.

CTSB is expressed in leader cells of SACC in 3D spheroid culture. To recapitulate the collective cell invasion of SACC in vitro, a 3D spheroid invasion assay was performed and the hanging drop technique, 96-well ultra-low attachment plates and soft agar-coated 96-well plates were used to generate multicellular spheroids. To investigate the spheroid formation efficiency of these three methods, the morphology of the spheroids was observed using transmitted light microscopy. After $48 \mathrm{~h}$, the multicellular spheroids generated by the hanging drop technique were irregular and loosely aggregated (Fig. $3 \mathrm{~A}$, panels a1), while those produced by the 96-well ultra-low attachment plates and soft agar-coated 96-well plates were regular and densely compacted (Fig. 3A, panels a2). Therefore, the multicellular spheroids generated by the 96-well ultra-low 
A
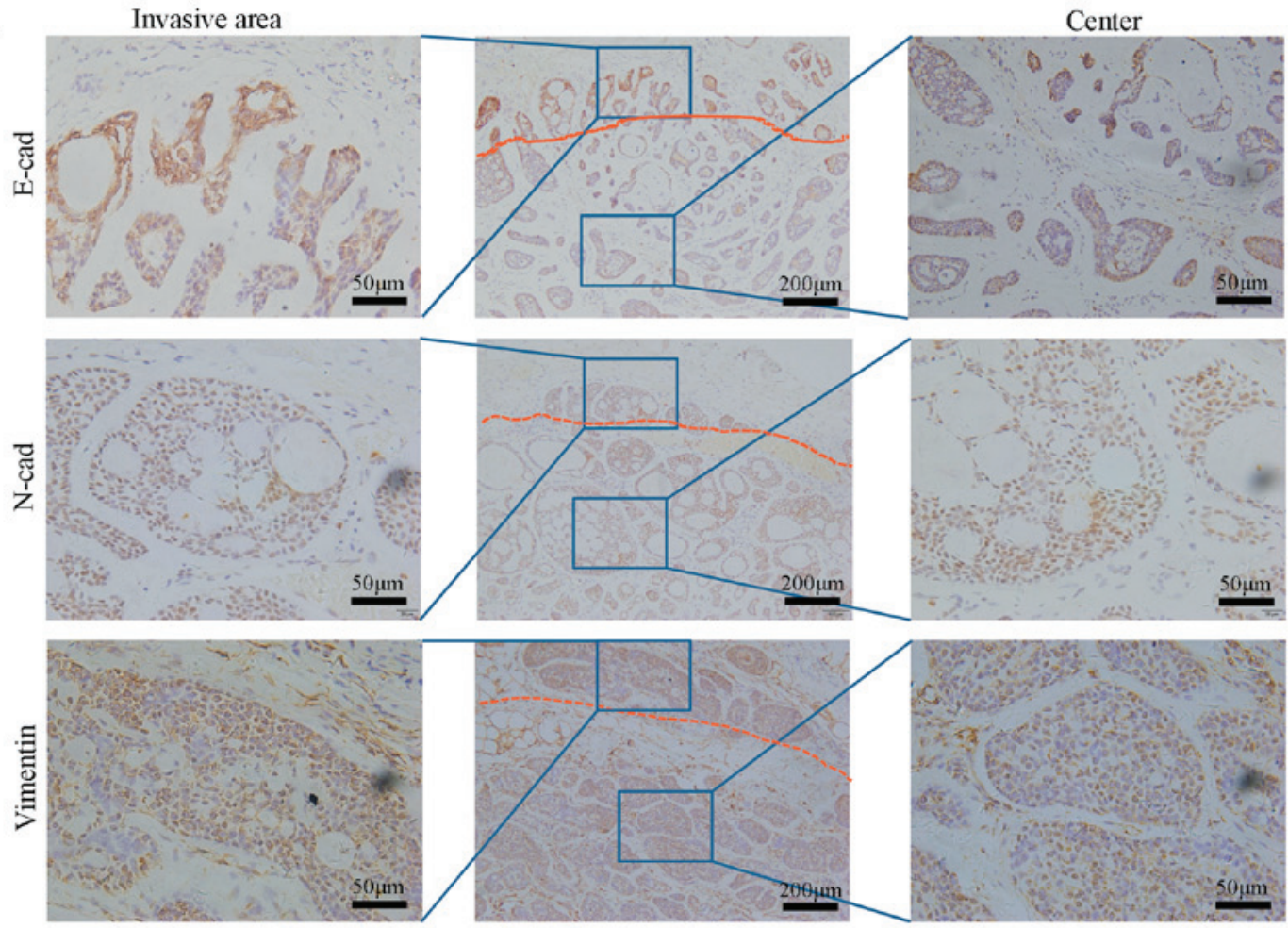

B

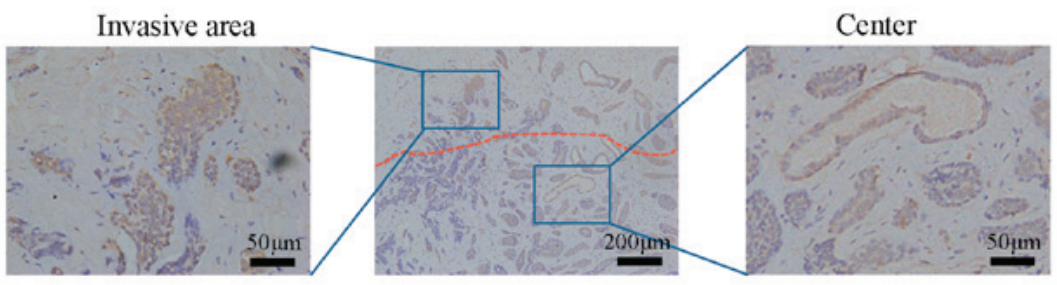

$\mathrm{C}$
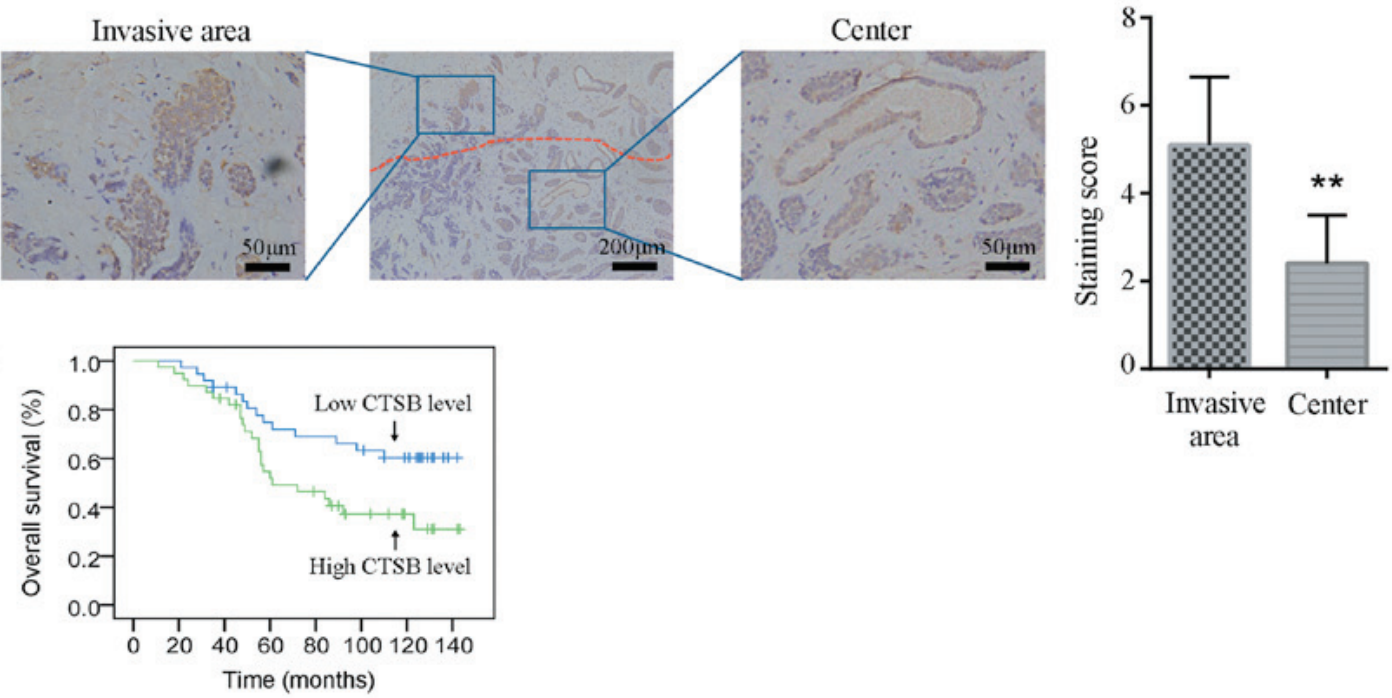

Figure 2. Invasive cancer cells of SACC exhibit partial EMT phenotypes and are defined by the expression of CTSB. IHC was performed on the SACC sections to detect the expression of (A) E-cadherin, N-cadherin, vimentin and (B) CTSB in the central and invasive areas. The left panels are the invasive areas and right panels are the central cancer areas. The red dotted line in the center panels divides the two different areas. The immunohistochemical staining of CTSB was quantified and comparison of the scores for the central and invasive areas was performed. Data are presented as the means \pm standard deviation. ${ }^{* *} \mathrm{P}<0.001$. (C) Kaplan-Meier plot of the survival times of the SACC patients with low or high CTSB levels. Significant differences were analyzed using the log-rank test $(\mathrm{P}<0.05)$. cad, cadherin; SACC, salivary adenoid cystic carcinoma; EMT, epithelial-mesenchymal transition; CTSB, cathepsin B; IHC, immunohistochemistry.

attachment plates and soft agar-coated 96-well plates were embedded in type I collagen gels to perform a 3D spheroid invasion assay.

After 16-24 h, the tumor organoids progressively extended multicellular strands of cancer cells from the margin into the collagen I and the leader cells were observed at the front of invasive strands (Fig. 3B). The close examination by light microscopy and SEM revealed that the leader cells exhibited an elongated phenotype and extended subcellular protrusions compared to the follower cells, which exhibited an epithelial cell morphology and few protrusions (Fig. 3B and C). In addition, the immunofluorescence staining demonstrated that the invasive cells retained E-cadherin expression, particularly the leader cells. Subsequently, we determined whether CTSB was overexpressed in the leader cells in the 3D spheroid invasion assay. Immunofluorescence staining revealed that the leader cells expressed CTSB in the cytoplasm, while the follower cells did not (Fig. 3D), indicating that CTSB may be a marker of leader cells in SACC collective cell invasion.

CTSB is required for leader cell formation in SACC collective cell invasion. To determine the contribution of 
Table I. Association between CTSB expression and the clinicopathological characteristics of patients with SACC.

\begin{tabular}{|c|c|c|c|c|}
\hline \multirow[b]{2}{*}{ Parameter } & \multirow[b]{2}{*}{$\mathrm{n}$} & \multicolumn{2}{|c|}{ CTSB expression } & \multirow[b]{2}{*}{ P-value } \\
\hline & & Low & High & \\
\hline $\operatorname{Sex}$ & & & & 0.484 \\
\hline Male & 31 & $17(54.84 \%)$ & $14(45.16 \%)$ & \\
\hline Female & 45 & $20(44.4 \%)$ & $25(55.56 \%)$ & \\
\hline Age (years) & & & & 0.815 \\
\hline$<60$ & 28 & $13(46.43 \%)$ & $15(53.57 \%)$ & \\
\hline$\geq 60$ & 48 & $24(50.00 \%)$ & $24(50.00 \%)$ & \\
\hline Tumor location & & & & 0.262 \\
\hline Major salivary & 36 & $15(41.67 \%)$ & $21(58.33 \%)$ & \\
\hline Minor salivary & 40 & $22(55.00 \%)$ & $18(45.00 \%)$ & \\
\hline Pathological type & & & & $0.034^{\mathrm{a}}$ \\
\hline Cribriform/tubular & 57 & $32(56.14 \%)$ & $25(43.86 \%)$ & \\
\hline Solid & 19 & $5(26.32 \%)$ & $14(73.68 \%)$ & \\
\hline TNM stage & & & & $0.043^{\mathrm{a}}$ \\
\hline I-II & 22 & $15(68.18 \%)$ & $7(31.82 \%)$ & \\
\hline III-IV & 54 & $22(40.74 \%)$ & $32(59.26 \%)$ & \\
\hline Perineural invasion & & & & $0.022^{\mathrm{a}}$ \\
\hline Yes & 24 & $10(41.67 \%)$ & $14(58.33 \%)$ & \\
\hline No & 52 & $37(71.15 \%)$ & $15(28.85 \%)$ & \\
\hline Recurrence & & & & $0.008^{\mathrm{a}}$ \\
\hline Yes & 19 & $4(21.05 \%)$ & $15(78.95 \%)$ & \\
\hline No & 57 & $33(57.89 \%)$ & $24(42.11 \%)$ & \\
\hline Distant metastasis & & & & $0.022^{\mathrm{a}}$ \\
\hline Yes & 17 & $5(29.41 \%)$ & $12(70.59 \%)$ & \\
\hline No & 49 & $32(65.31 \%)$ & $17(34.69 \%)$ & \\
\hline
\end{tabular}

${ }^{a}$ Indicates statistical significance $(\mathrm{P}<0.05)$. SACC, salivary adenoid cystic carcinoma.

CTSB to SACC-83 cell invasion, three siRNA duplexes for CTSB were characterized. All of them efficiently knocked down their target, as determined by western blot analysis and RT-qPCR. Among the three siRNA duplexes, siRNA 3 exhibited the highest efficiency and was used to perform the subsequent experiments (Fig. S1). In the wound healing and Transwell assays, siCTSB transfection effectively reduced the migratory and invasive ability of the SACC-83 cells compared to the control siRNA-transfected cells (Fig. 4A and B). To determine whether CTSB is required for leader cell formation, the SACC-83 cells were labeled with either GFP or mCherry and mixing experiments were performed by co-culturing the control GFP-expressing cells with siCTSB-transfected mCherry-expressing cells, or by co-culturing the control mCherry-expressing cells with siCTSB-transfected GFP-expressing cells (Fig. 4C). The control GFP- and mCherry-expressing cells were observed at the leading tip of the invasive strands in 76.3 and $74.8 \%$ cases, respectively, while the mCherry- and GFP-expressing cells with siCTSB treatment were only observed at the front of the invasive strands in 23.7 and $25.2 \%$ cases, respectively (Fig. 4D).
Knockdown of CTSB inhibits ECM remodeling. In the present study, the effects of CTSB depletion on protease- and force-mediated ECM remodeling were investigated. The SACC-83 cells transfected with siCTSB expressed lower levels of MMP-9 at the mRNA and protein level compared to those transfected with control siRNA (Fig. 5A and B). Force-mediated ECM remodeling was assessed by microscopic analysis of the extent of matrix contraction. The results revealed that there was a significant reduction in ECM contraction in response to knockdown of CTSB (Fig. 5C). Phalloidin staining and SEM were used to examine the effects of siCTSB transfection on cell cytoskeletal organization and cell morphology (Fig. 5D and E). The results of SEM analysis demonstrated that the SACC-83 cells transfected with siCTSB lost their elongated phenotype, but exhibited an epithelial cell morphology and a reduced number of subcellular protrusions. CTSB siRNA transfection disrupted the normal cytoskeletal organization of the SACC-83 cells. It is widely established that Rho-ROCK function and cytoskeletal organization play a key role in force-mediated ECM remodeling $(29,30)$. The depletion of CTSB inhibited the expression of focal adhesion kinase (FAK), an adaptor molecule involved in connecting 
A a-1

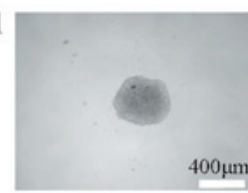

a-2

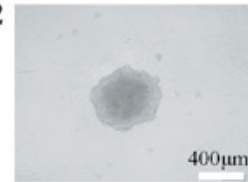

a-3

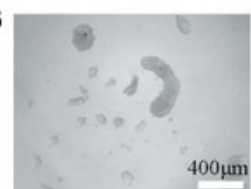

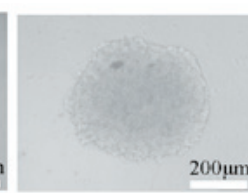
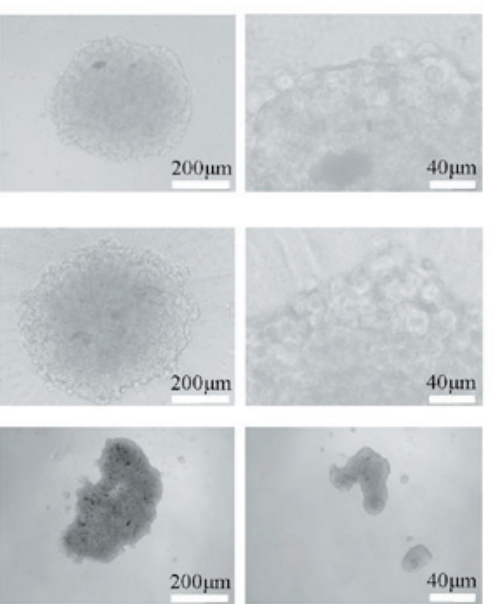

B
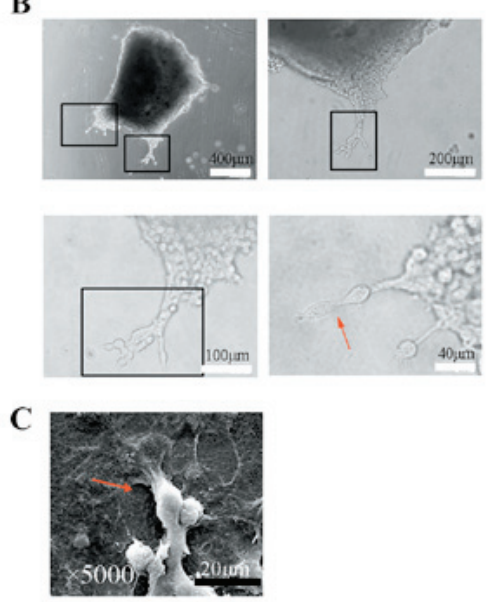

D

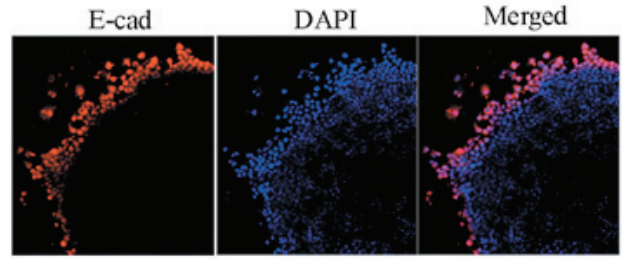

CTSB

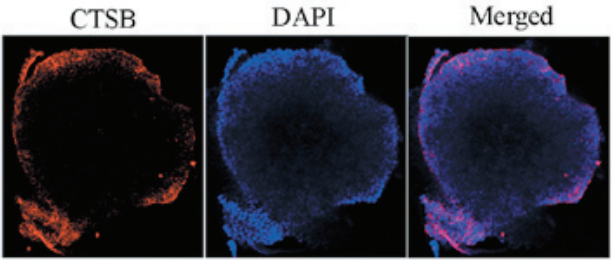

Figure 3. Leader cells of SACC are molecularly defined by the expression of CTSB in 3D spheroid culture. (A) The SACC cells cultured in 96-well ultra-low attachment plates and soft agar-coated 96-well plates formed regular and densely compacted multicellular spheroids. The SACC-83 cells were cultured with (a-1) the hanging drop technique, or in (a-2) 96-well ultra-low attachment plates and (a-3) soft agar-coated 96-well plates for 48 h. (B) The morphology and structure of the tumor spheroids embedded in collagen I for $48 \mathrm{~h}$, as observed under light microscopy. The tumor cells collectively invaded from the tumor organoid and leader cells were observed at the front of these invasive strands of SACC. The leader cells exhibited an elongated phenotype and extended subcellular protrusions. The red arrow indicates leader cells. (C) The morphology of the SACC-83 leader cells, as observed under a scanning electron microscope. The leader cells exhibited an elongated morphology with extending protrusions, whereas the follower cells lacked protrusions. The red arrow indicates leader cells. (D) The 3D spheroids of SACC-83 cells were stained with E-cadherin and CTSB by immunofluorescent staining. The leader SACC-83 cells retained the expression of E-cadherin (left panel) and were defined by the expression of CTSB (right panel), whereas the follower cells negatively expressed CTSB. cad, cadherin; SACC, salivary adenoid cystic carcinoma; CTSB, cathepsin B.

integrins to filamentous actin in the cytoskeleton. Furthermore, RT-qPCR revealed that the expression levels of RhoA, ROCK1 and ROCK 2 were significantly downregulated following transfection with siCTSB (Fig. 5A).

\section{Discussion}

The collective invasion of multicellular groups that are comprised of leader cells and follower cells is critical for cancer metastasis. Collective cell invasion requires the guidance of leader cells; however, the molecular markers that define leader cells and the mechanisms through which leader cells promote collective cell invasion remain unknown. In the present study, CTSB was revealed to be overexpressed in the invasive front compared to the central area of SACC and this was associated with a poor prognosis of patients with the disease. The knockdown of CTSB impaired the formation of leader cells, disrupted cytoskeletal organization, altered cell morphology, and inhibited ECM remodeling through the downregulation of MMP-9, FAK and Rho/ROCK function. These findings demonstrate that CTSB may be a useful marker of leader cells in the collective invasion of SACC, and may be involved in the regulation of protease- and force-mediated ECM remodeling.

EMT is a key event in cancer invasion and is characterized by the acquisition of mesenchymal phenotypes and the loss of cell-to-cell adhesions. However, increasing evidence has demonstrated that collective cell invasion is another model of cancer invasion $(14,31)$. In the present study, neoplastic epithelial cells invaded into the adjacent tissue as multicellular units in the SACC samples and retained E-cadherin expression. Notably, the IHC results revealed that the cancer cells at the invasive front lacked a complete EMT signature. In the 3D spheroid invasion assay, the leader cells exhibited a more elongated phenotype, but retained E-cadherin expression, indicating a partial EMT phenotype. These results are consistent with those of some previous studies, in which leader cells also lacked a complete EMT signature and could not be identified by canonical mesenchymal markers $(8,32)$. It has been reported that EMT is rarely equally pronounced in the entire tumor tissue, and partial EMT is more frequent in cancer than complete EMT (7,33). The cancer cells undergoing partial EMT acquire the expression of mesenchymal markers and maintain certain epithelial characteristics simultaneously (6). On the other hand, previous studies have revealed that metastatic cancer cells with mesenchymal features must undergo the reverse transition, mesenchymal-epithelial transition (MET), at the secondary site (34-36). MET has been demonstrated to increase the survival of these cells and recapitulate the pathology of the primary tumors in numerous types of cancer, including breast cancer, small cell lung cancer and ovarian cancer $(34,35,37)$. However, few studies have focused on the role of MET in SACC metastases and further studies are therefore required. 
A
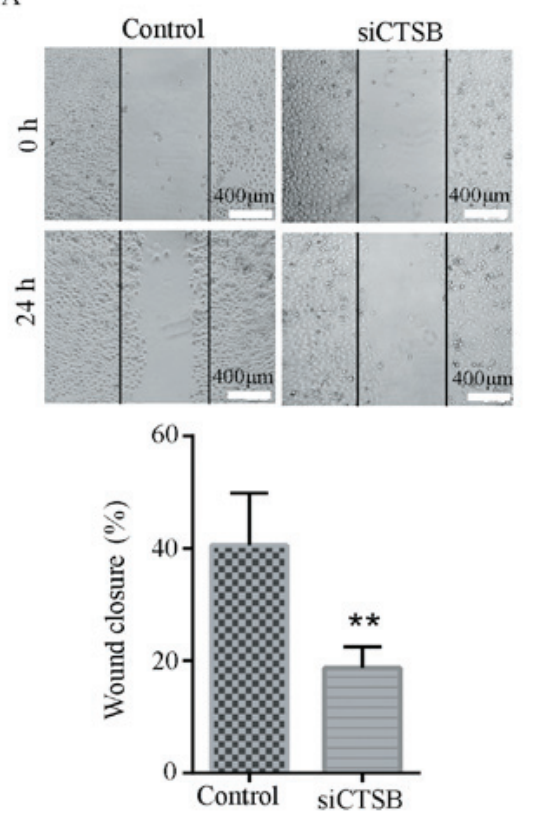

B
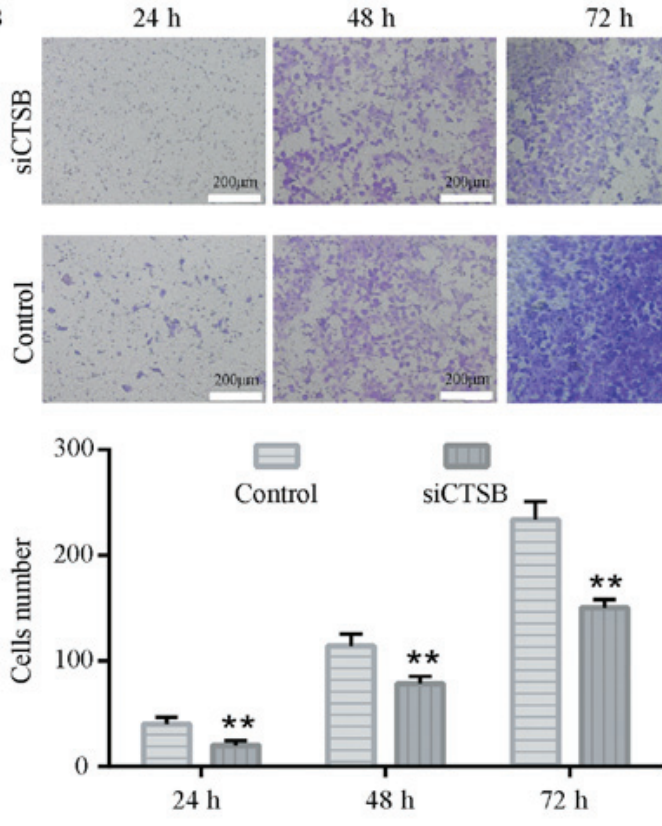

$48 \mathrm{~h}$
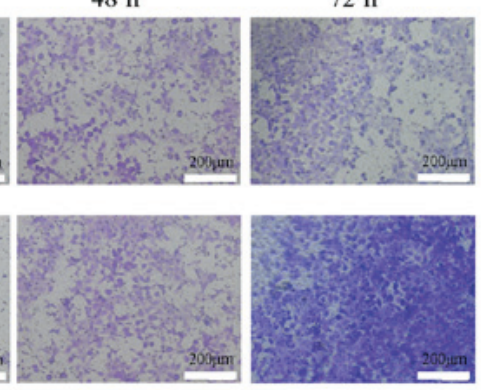
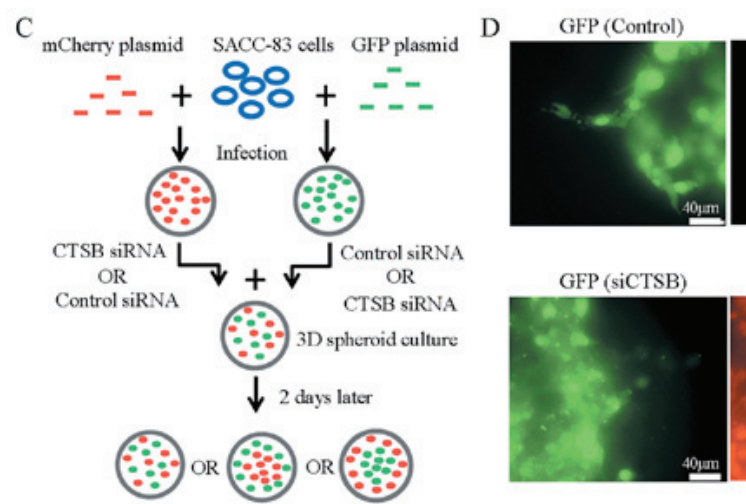

mCherry (siCTSB)

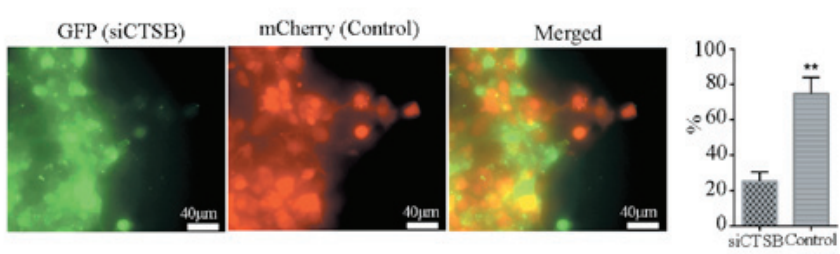

Figure 4. CTSB is required for leader cell formation in SACC collective cell invasion. (A) In vitro wound healing assay. SACC-83 cells transfected with siCTSB or control siRNA were seeded and after $24 \mathrm{~h}$, cell migration was measured. The quantitative data demonstrated that the knockdown of CTSB inhibited the migratory ability of the SACC-83 cells. Data are presented as the means \pm standard deviation $(n=3) .{ }^{* *} \mathrm{P}<0.001$. (B) Transwell assay. Control SACC-83 cells and siCTSB-transfected SACC-83 cells were suspended in medium and seeded in Transwell chambers. After 24, 48 and $73 \mathrm{~h}$, the number of cells that had invaded the lower surface of the filters was counted. The quantitative data revealed that the knockdown of CTSB inhibited the invasion ability of the SACC-83 cells. Data are presented as the means \pm standard deviation $(n=3){ }^{* * *} \mathrm{P}<0.001$. (C) Schema of the mixed spheroid invasion assay of the SACC- 83 cells. Lentivirus infection was performed to label separate pools of SACC- 83 cells with mCherry or GFP. Mixed spheroid culture was performed by co-culturing control GFP-expressing cells with siCTSB-transfected mCherry-expressing cells, or by co-culturing control mCherry-expressing cells with siCTSB-transfected GFP-expressing cells. The leader cells were identified using a fluorescent microscope. (D) Confocal laser microscopy of the mixed spheroid invasion assay. The control GFP- and mCherry-expressing cells were observed at the leading tip of the invasive strands more frequently than the siCTSB GFP- or mCherry-expressing cells. Data are presented as the mean \pm standard deviation. ${ }^{* *} \mathrm{P}<0.001$, using Student's t-tests. CTSB, cathepsin B; SACC, salivary adenoid cystic carcinoma.

The invasive front of a tumor represents the tumor cell-host organ interface, in which tumor cells invade into the surrounding tissue by secreting proteases, such as MMPs and CTSB $(38,39)$. It has been reported that tumor budding or dedifferentiation at the invasion front can be a predictor of poor outcomes in colorectal cancers (38). Previous studies have confirmed that CTSB is overexpressed in different types of cancer, including breast cancer (21), non-small cell lung carcinoma (40), colorectal cancer (41) and oral squamous cell carcinoma (42), and it indicates poor outcomes for patients. The association between an increased CTSB expression and the looseness of cancerous interstitial tissue also indicates the pivotal roles of CTSB in cancer invasion and metastasis (21). CTSB levels are frequently elevated at the invasive edge of tumors and during tumor budding in colorectal cancer $(38,43)$.
In the present study, the data demonstrated that CTSB was overexpressed in the cytoplasm of SACC cells at the invasive front compared to the tumor center and was associated with a poor prognosis of patients with SACC. Furthermore, CTSB overexpression was associated with perineural invasion (PNI) in SACC. PNI, a hallmark of SACC, is an independent indicator of tumor recurrence and a poor prognosis (44-46). The role of cathepsins in PNI of SACC was also demonstrated in our previous study, in which cathepsin D was overexpressed in the nerve invasion frontier and associated with a poor prognosis of patients with SACC (47).

In collective cell invasion, the multicellular units are considered as phenotypically heterogeneous cancer cell populations and the leader cells are protrusive at the front of the invasive strands (32). The present study demonstrated 


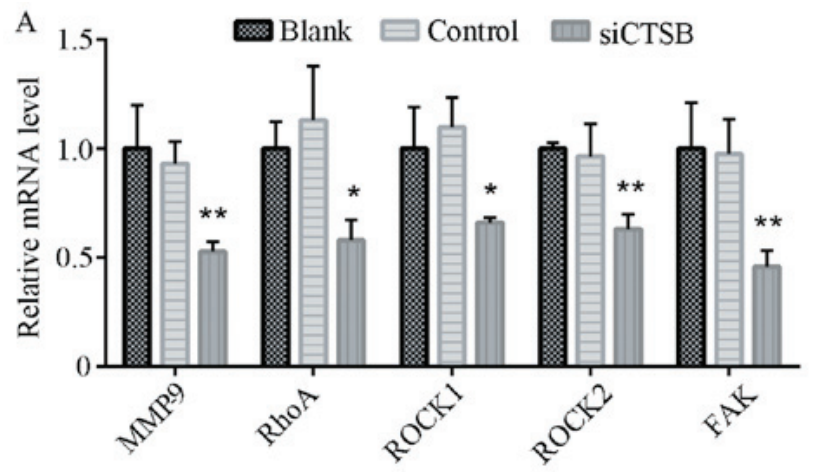

B

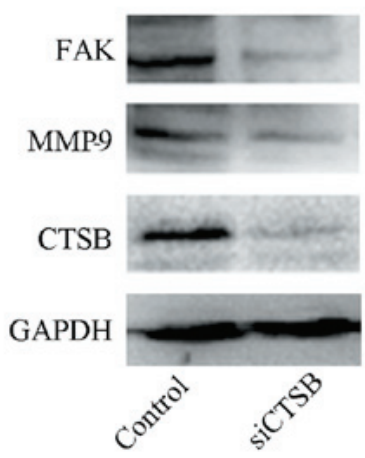

$\mathrm{C}$
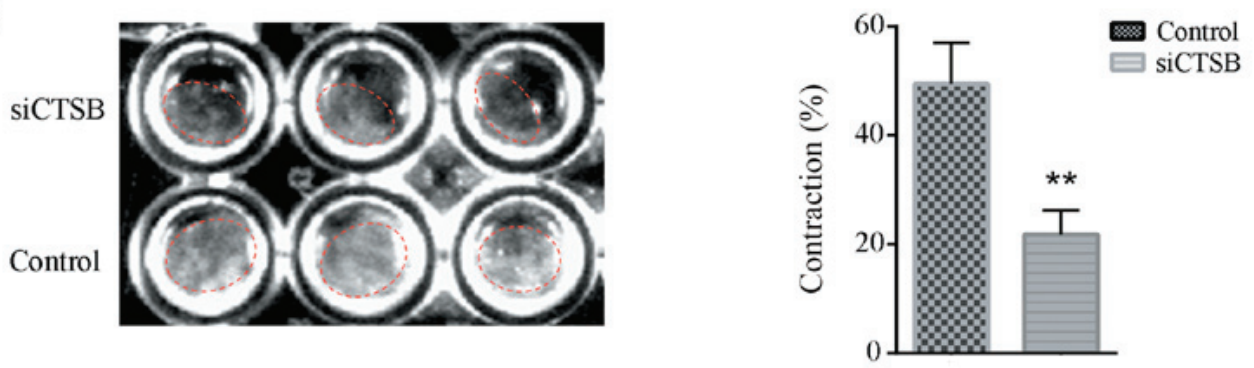

D

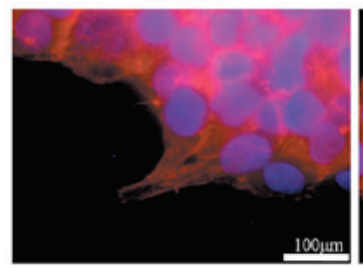

siCTSB

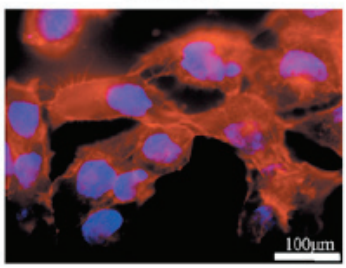

E

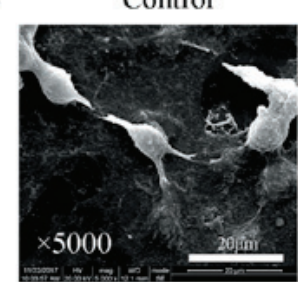

siCTSB

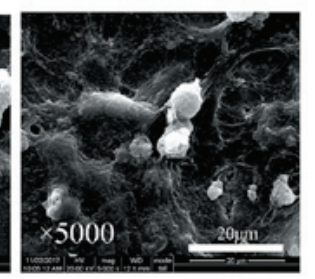

Figure 5. Knockdown of CTSB inhibits ECM remodeling. (A) The expression levels of MMP-9, RhoA, ROCK1, ROCK2 and FAK mRNA in SACC-83 cells transfected with siCTSB or a blank control. The knockdown of CTSB inhibited the mRNA levels of the ECM remodeling-related genes. Data are presented as the means \pm standard deviation. ${ }^{*} \mathrm{P}<0.05,{ }^{* *} \mathrm{P}<0.001$. (B) Western blot analysis of CTSB, MMP-9 and FAK protein in SACC-83 cells transfected with siCTSB or a blank control. The knockdown of CTSB inhibited the levels of ECM remodeling-related proteins. (C) An ECM contraction assay of force-mediated ECM remodeling. The percentage of contraction area per well revealed that contraction was inhibited in response to knockdown of CTSB. Data are presented as the means \pm standard deviation. ${ }^{* *} \mathrm{P}<0.001$. (D) CBST knockdown in SACC- 83 cells cultured on glass coverslips reduced cytoskeletal F-actin staining. (E) The morphologic alteration of SACC-83 cells after CBST knockdown. siCTSB-treated SACC-83 cells exhibited epithelial cell morphology and a reduced number of subcellular protrusions compared to the control group. CTSB, cathepsin B; ECM, extracellular matrix; MMP, matrix metalloproteinase; FAK, focal adhesion kinase; SACC, salivary adenoid cystic carcinoma.

that leader cells of SACC were located in the invasion edge and exhibit a more elongated phenotype with subcellular protrusions compared to follower cells. Furthermore, in the 3D spheroid invasion assay, CTSB was overexpressed in the leader cells, which corresponds with the high expression of CTSB at the invasive front in SACC. Previous studies have revealed that cytokeratin-14, p63 and integrin $\beta$ are overexpressed in leader cells of breast cancer $(14,48)$. These results suggest that leader cells are specialized cells that express particular markers, including CTSB, cytokeratin-14, p63 and integrin $\beta$, and CTSB may be a marker of leader cells in SACC. In addition, IHC and immunofluorescence staining in the present study revealed that CTSB was localized in the cytoplasm of leader cells. In previous studies, CTSB has been identified in perinuclear lysosomes, vesicles, mitochondria and the cell periphery (20). CTSB in the lysosomes can facilitate autophagy, while in the nucleus it is involved in the nuclear scaffold and cell division (49). However, the multifaceted roles of CTSB in leader cells of SACC have not yet been detected and therefore further studies are required.
CTSB has been shown to mediate the dissemination and invasion of cancer cells by degrading components of the ECM, and it plays an active role in EMT and tumor angiogenesis (50-53). Consistent with the findings of previous studies, the results of the present study demonstrated that the knockdown of CTSB inhibited the migratory and invasive abilities of SACC cells. The degradation of basement membranes and connective tissues by various proteases is considered as a prerequisite for the collective invasion of cancer cells. In addition, CTSB has been implicated in the initiation of the proteolytic cascade that involves uPA, plasminogen and plasmin, which indicates that CTSB can activate other ECM-degrading proteases (54). MMPs are key proteases involved in proteolytically cleaving ECM components and reducing ECM barriers during cancer cell invasion (55). The expression levels of MMP-9 are elevated in various types of cancer, including breast cancer, head and neck carcinoma and colon cancer, and they indicate a poor prognosis in these patients $(38,56,57)$. In a previous study, CTSB was revealed to destroy the inhibitors of MMPs and maintain a high level 
of MMPs, thereby promoting ECM degradation in human articular chondrocytes (53). Consistent with this study, the present study demonstrated that CTSB knockdown inhibits mRNA and protein expression of MMP-9, indicating that apart from its direct proteolytic activity, CTSB may also serve an important role in MMP-9-mediated proteolysis. Another MMP member, MMP-14, has been identified as a key regulator in collective cell migration by sterically generating tube-like microtracks and enlarging microtracks into macrotracks for accommodation of cell groups $(17,58)$.

In addition to protease-mediated ECM remodeling, force-mediated ECM remodeling is another major mechanism of ECM remodeling (15). Tumor cells generate contractile force to deform collagen fibers and move through dense ECM without proteolysis (59). ROCK-dependent force-mediated ECM remodeling is specifically required for collective cell invasion $(58,59)$. The function of Rho-ROCK has been reported to regulate myosin activity, which is essential for the formation of cell protrusions and ECM remodeling $(17,29,30)$. Previous studies have revealed that RhoA and ROCKs play an important role in mediating collective cell invasion by controlling leader-follower cell hierarchy, multicellular contractility and mechanocoupling $(60,61)$. In the present study, CTSB knockdown inhibited the levels of Rho and ROCK, reduced the extension of subcellular protrusions and disrupted the normal cytoskeletal organization of SACC-83 cells, which indicates that CTSB is involved in ROCK-dependent force-mediated ECM remodeling. FAK is an intracellular protein tyrosine kinase and it functions as a key regulator of integrin-dependent matrix adhesions (62). Previous studies have demonstrated that FAK expression is elevated in numerous types of cancer and is considered as an indicator of a poor prognosis for these patients $(63,64)$. Another study revealed that FAK may regulate collective cell invasion by modulating cell-cell adhesion through controlling E-cadherin internalization (65). The present study indicated that the knockdown of CTSB in SACC-83 cells inhibited FAK expression. This result is in agreement with the findings of a previous study, in which the downregulation of CTSB induced cytoskeletal disorganization by downregulating the expression of FAK (66). These findings suggest that FAK may be involved in CTSB-mediated ECM remodeling.

In conclusion, the findings of this study demonstrate that CTSB is overexpressed in the invasive front of SACC and is associated with a poor prognosis of patients with SACC. The knockdown of CTSB disrupts cytoskeletal organization, alters cell morphology, inhibits ECM remodeling and impairs the formation of leader cells. The present study provides evidence that CTSB may define leader cells in SACC and is required for collective cell invasion as a potential key regulator of ECM remodeling. However, further studies are required in order to elucidate the underlying mechanisms. In addition, further studies are warranted to explore the effects of CTSB-specific inhibitors on tumor-bearing mice which may shed light on SACC therapy by targeting CTSB.

\section{Acknowledgements}

Not applicable.

\section{Funding}

This study was supported by National Natural Science Foundation of China grants (nos. 81572650, 81672672, 81772891, 81502357 and 81621062), the Natural Science Foundation of Zhejiang Province (Q142114001), the Zhoushan Science and Technology Bureau Project (2014C31068), the Fundamental Research Funds for the Central Universities (2017), and by the State Key Laboratory of Oral Diseases Special Funded Projects (2016).

\section{Availability of data and materials}

The datasets used during this study are available from the corresponding author on reasonable request.

\section{Authors' contributions}

JSW, MiZ and YLT conceived the study, participated in its design and wrote the manuscript. JSW, ZFL, HFW, XP, JBW and XHY performed the research. SSW, MeZ, XY, MXC, YJT, XHL interpreted the results, analyzed data and reviewed the manuscript. All authors have read and approved the final manuscript.

\section{Ethics approval and consent to participate}

The use of human tissue samples and clinical data were obtained with written informed consent, and the protocols were approved by the Institutional Ethics Committee of the West China Medical Center, Sichuan University, China (WCHSIRB-D-2016-176).

\section{Patient consent for publication}

Not applicable.

\section{Competing interests}

The authors declare that they have no competing interests.

\section{References}

1. Hanahan D and Weinberg RA: Hallmarks of cancer: The next generation. Cell 144: 646-674, 2011.

2. Sahai E: Illuminating the metastatic process. Nat Rev Cancer 7: 737-749, 2007.

3. Thiery JP: Epithelial-mesenchymal transitions in tumour progression. Nat Rev Cancer 2: 442-454, 2002.

4. Wong IY, Javaid S, Wong EA, Perk S, Haber DA, Toner M and Irimia D: Collective and individual migration following the epithelial-mesenchymal transition. Nat Mater 13: 1063-1071, 2014.

5. Lamouille S, Xu J and Derynck R: Molecular mechanisms of epithelial-mesenchymal transition. Nat Rev Mol Cell Biol 15: 178-196, 2014.

6. Revenu C and Gilmour D: EMT 2.0: Shaping epithelia through collective migration. Curr Opin Genet Dev 19: 338-342, 2009.

7. Krakhmal NV, Zavyalova MV, Denisov EV, Vtorushin SV and Perelmuter VM: Cancer Invasion: Patterns and Mechanisms. Acta Naturae 7: 17-28, 2015.

8. Westcott JM, Prechtl AM, Maine EA, Dang TT, Esparza MA, Sun H, Zhou Y, Xie Y and Pearson GW: An epigenetically distinct breast cancer cell subpopulation promotes collective invasion. J Clin Invest 125: 1927-1943, 2015. 
9. Rørth P: Collective guidance of collective cell migration. Trends Cell Biol 17: 575-579, 2007.

10. Mayor R and Etienne-Manneville S: The front and rear of collective cell migration. Nat Rev Mol Cell Biol 17: 97-109, 2016.

11. Khalil AA and Friedl P: Determinants of leader cells in collective cell migration. Integr Biol (Camb) 2: 568-574, 2010.

12. Gov NS: Collective cell migration patterns: Follow the leader. Proc Natl Acad Sci USA 104: 15970-15971, 2007.

13. Kim YH, Choi YW, Lee J, Soh EY, Kim JH and Park TJ: Senescent tumor cells lead the collective invasion in thyroid cancer. Nat Commun 8: 15208, 2017.

14. Cheung KJ, Gabrielson E, Werb Z and Ewald AJ: Collective invasion in breast cancer requires a conserved basal epithelial program. Cell 155: 1639-1651, 2013.

15. Wu JS, Sheng SR, Liang XH and Tang YL: The role of tumor microenvironment in collective tumor cell invasion. Future Oncol 13: 991-1002, 2017.

16. Kumar S, Kapoor A, Desai S, Inamdar MM and Sen S: Proteolytic and non-proteolytic regulation of collective cell invasion: Tuning by ECM density and organization. Sci Rep 6: 19905, 2016.

17. Wolf K, Wu YI, Liu Y, Geiger J, Tam E, Overall C, Stack MS and Friedl P: Multi-step pericellular proteolysis controls the transition from individual to collective cancer cell invasion. Nat Cell Biol 9: 893-904, 2007.

18. Fisher KE, Sacharidou A, Stratman AN, Mayo AM, Fisher SB Mahan RD, Davis MJ and Davis GE: MT1-MMP- and Cdc42-dependent signaling co-regulate cell invasion and tunnel formation in 3D collagen matrices. J Cell Sci 122: 4558-4569, 2009.

19. Premzl A, Zavašnik-Bergant $\mathrm{V}$, Turk $\mathrm{V}$ and Kos $\mathrm{J}$ : Intracellular and extracellular cathepsin B facilitate invasion of MCF-10A neoT cells through reconstituted extracellular matrix in vitro. Exp Cell Res 283: 206-214, 2003.

20. Aggarwal N and Sloane BF: Cathepsin B: Multiple roles in cancer. Proteomics Clin Appl 8: 427-437, 2014.

21. Yano M, Hirai K, Naito Z, Yokoyama M, Ishiwata T, Shiraki Y, Inokuchi $M$ and Asano G: Expression of cathepsin $B$ and cystatin $\mathrm{C}$ in human breast cancer. Surg Today 31: 385-389, 2001.

22. Strojnik T, Kos J, Zidanik B, Golouh R and Lah T: Cathepsin B immunohistochemical staining in tumor and endothelial cells is a new prognostic factor for survival in patients with brain tumors. Clin Cancer Res 5: 559-567, 1999.

23. Kos J, Nielsen HJ, Krasovec M, Christensen IJ, Cimerman N, Stephens RW and Brünner N: Prognostic values of cathepsin B and carcinoembryonic antigen in sera of patients with colorecta cancer. Clin Cancer Res 4: 1511-1516, 1998.

24. Tsukamoto H, Kato T, Enomoto A, Nakamura N, Shimono Y, Jijiwa M, Asai N, Murakumo Y, Shibata K, Kikkawa F, et al: Expression of Ret finger protein correlates with outcomes in endometrial cancer. Cancer Sci 100: 1895-1901, 2009.

25. Iwakoshi A, Murakumo Y, Kato T, Kitamura A, Mii S, Saito S, Yatabe $\mathrm{Y}$ and Takahashi M: RET finger protein expression is associated with prognosis in lung cancer with epidermal growth factor receptor mutations. Pathol Int 62: 324-330, 2012.

26. Søland TM, Brusevold IJ, Koppang HS, Schenck K and Bryne M: Nerve growth factor receptor (p75 NTR) and pattern of invasion predict poor prognosis in oral squamous cell carcinoma. Histopathology 53: 62-72, 2008.

27. Korff T and Augustin HG: Integration of endothelial cells in multicellular spheroids prevents apoptosis and induces differentiation. J Cell Biol 143: 1341-1352, 1998.

28. Hooper S, Gaggioli C and Sahai E: A chemical biology screen reveals a role for Rab21-mediated control of actomyosin contractility in fibroblast-driven cancer invasion. Br J Cancer 102: 392-402, 2010.

29. Meshel AS, Wei Q, Adelstein RS and Sheetz MP: Basic mechanism of three-dimensional collagen fibre transport by fibroblasts. Nat Cell Biol 7: 157-164, 2005.

30. Russo JM, Florian P, Shen L, Graham WV, Tretiakova MS Gitter AH, Mrsny RJ and Turner JR: Distinct temporal-spatial roles for rho kinase and myosin light chain kinase in epithelial purse-string wound closure. Gastroenterology 128: 987-1001, 2005

31. Clark AG and Vignjevic DM: Modes of cancer cell invasion and the role of the microenvironment. Curr Opin Cell Biol 36: 13-22, 2015.

32. Konen J, Summerbell E, Dwivedi B, Galior K, Hou Y, Rusnak L, Chen A, Saltz J, Zhou W, Boise LH, et al: Image-guided genomics of phenotypically heterogeneous populations reveals vascular signalling during symbiotic collective cancer invasion. Nat Commun 8: 15078, 2017.
33. Krebs MG, Metcalf RL, Carter L, Brady G, Blackhall FH and Dive C: Molecular analysis of circulating tumour cells-biology and biomarkers. Nat Rev Clin Oncol 11: 129-144, 2014.

34. Hamilton G, Hochmair M, Rath B, Klameth L and Zeillinger R: Small cell lung cancer: Circulating tumor cells of extended stage patients express a mesenchymal-epithelial transition phenotype. Cell Adhes Migr 10: 360-367, 2016.

35. Li Y, Gong W, Ma X, Sun X, Jiang H and Chen T: Smad7 maintains epithelial phenotype of ovarian cancer stem-like cells and supports tumor colonization by mesenchymal-epithelial transition. Mol Med Rep 11: 309-316, 2015.

36. Aokage K, Ishii G, Ohtaki Y, Yamaguchi Y, Hishida T, Yoshida J, Nishimura M, Nagai K and Ochiai A: Dynamic molecular changes associated with epithelial-mesenchymal transition and subsequent mesenchymal-epithelial transition in the early phase of metastatic tumor formation. Int J Cancer 128: 1585-1595, 2011.

37. Souid S, Elsayed HE, Ebrahim HY, Mohyeldin MM, Siddique AB, Karoui H, El Sayed KA and Essafi-Benkhadir K: $13^{1}$-Oxophorbine protopheophorbide A from Ziziphus lotus as a novel mesenchymal-epithelial transition factor receptor inhibitory lead for the control of breast tumor growth in vitro and in vivo. Mol Carcinog 57: 1507-1524, 2018.

38. Guzińska-Ustymowicz K: MMP-9 and cathepsin B expression in tumor budding as an indicator of a more aggressive phenotype of colorectal cancer (CRC). Anticancer Res 26 (2B): 1589-1594, 2006.

39. Ivanovska J, Zlobec I, Forster S, Karamitopoulou E, Dawson H, Koelzer VH, Agaimy A, Garreis F, Söder S, Laqua W, et al: DAPK loss in colon cancer tumor buds: Implications for migration capacity of disseminating tumor cells. Oncotarget 6 : 36774-36788, 2015.

40. Werle B, Kraft C, Lah TT, Kos J, Schanzenbächer U, Kayser K, Ebert W and Spiess E: Cathepsin B in infiltrated lymph nodes is of prognostic significance for patients with nonsmall cell lung carcinoma. Cancer 89: 2282-2291, 2000.

41. Zhang J, He P, Zhong Q, Li K, Chen D, Lin Q and Liu W: Increasing Cystatin C and Cathepsin B in Serum of Colorectal Cancer Patients. Clin Lab 63: 365-371, 2017.

42. Yang WE, Ho CC, Yang SF, Lin SH, Yeh KT, Lin CW and Chen MK: Cathepsin B Expression and the Correlation with Clinical Aspects of Oral Squamous Cell Carcinoma. PLoS One 11: e0152165, 2016.

43. Guzińska-Ustymowicz K, Zalewski B, Kasacka I, Piotrowski Z and Skrzydlewska E: Activity of cathepsin B and D in colorectal cancer: Relationships with tumour budding. Anticancer Res 24 (5A): 2847-2851, 2004.

44. Zhang M, Zhu ZL, Gao XL, Wu JS, Liang XH and Tang YL: Functions of chemokines in the perineural invasion of tumors (Review). Int J Oncol: Mar 8, 2018 (Epub ahead of print).

45. Shen Z, Li T, Chen D, Jia S, Yang X, Liang L, Chai J, Cheng X, Yang $X$ and Sun M: The CCL5/CCR5 axis contributes to the perineural invasion of human salivary adenoid cystic carcinoma. Oncol Rep 31: 800-806, 2014

46. Shan C, Wei J, Hou R, Wu B, Yang Z, Wang L, Lei D and Yang X: Schwann cells promote EMT and the Schwann-like differentiation of salivary adenoid cystic carcinoma cells via the BDNF/TrkB axis. Oncol Rep 35: 427-435, 2016.

47. Zhang M, Wu JS, Yang X, Pang X, Li L, Wang SS, Wu JB, Tang YJ, Liang XH, Zheng M, et al: Overexpression Cathepsin D Contributes to Perineural Invasion of Salivary Adenoid Cystic Carcinoma. Front Oncol 8: 492, 2018.

48. Kato T, Enomoto A, Watanabe T, Haga H, Ishida $\mathrm{S}$, Kondo Y, Furukawa K, Urano T, Mii S, Weng L, et al: TRIM27/MRTF-B-dependent integrin $\beta 1$ expression defines leading cells in cancer cell collectives. Cell Rep 7: 1156-1167, 2014

49. Gondi CS and Rao JS: Cathepsin B as a cancer target. Expert Opin Ther Targets 17: 281-291, 2013

50. Podgorski I and Sloane BF: Cathepsin B and its role(s) in cancer progression. Biochem Soc Symp 70: 263-276, 2003.

51. Poreba W, Gawlik K and Gutowicz J: Cathepsin B and neoplasm invasiveness. Postepy Biochem 48: 111-120, 2002 (In Polish).

52. Wellner U, Schubert J,Burk UC, SchmalhoferO,Zhu F, Sonntag A, Waldvogel B, Vannier C, Darling D, zur Hausen A, et al: The EMT-activator ZEB1 promotes tumorigenicity by repressing stemness-inhibiting microRNAs. Nat Cell Biol 11: 1487-1495, 2009.

53. Kostoulas G, Lang A, Nagase H and Baici A: Stimulation of angiogenesis through cathepsin B inactivation of the tissue inhibitors of matrix metalloproteinases. FEBS Lett 455: 286-290, 1999. 
54. Somanna A, Mundodi V and Gedamu L: Functional analysis of cathepsin B-like cysteine proteases from Leishmania donovani complex. Evidence for the activation of latent transforming growth factor beta. J Biol Chem 277: 25305-25312, 2002.

55. Tummalapalli P, Spomar D, Gondi CS, Olivero WC, Gujrati M, Dinh DH and Rao JS: RNAi-mediated abrogation of cathepsin B and MMP-9 gene expression in a malignant meningioma cell line leads to decreased tumor growth, invasion and angiogenesis. Int J Oncol 31: 1039-1050, 2007

56. Vento SI, Jouhi L, Mohamed H, Haglund C, Mäkitie AA, Atula T, Hagström J and Mäkinen LK: MMP-7 expression may influence the rate of distant recurrences and disease-specific survival in HPV-positive oropharyngeal squamous cell carcinoma. Virchows Arch 472: 975-981, 2018.

57. Upmanyu N, Bulldan A, Papadopoulos D, Dietze R, Malviya VN and Scheiner-Bobis G: Impairment of the Gna11-controlled expression of claudin-1 and MMP-9 and collective migration of human breast cancer MCF-7 cells by DHEAS. J Steroid Biochem Mol Biol 182: 50-61, 2018.

58. Gaggioli C, Hooper S, Hidalgo-Carcedo C, Grosse R, Marshall JF, Harrington K and Sahai E: Fibroblast-led collective invasion of carcinoma cells with differing roles for RhoGTPases in leading and following cells. Nat Cell Biol 9: 1392-1400, 2007.

59. Wyckoff JB, Pinner SE, Gschmeissner S, Condeelis JS and Sahai E: ROCK- and myosin-dependent matrix deformation enables protease-independent tumor-cell invasion in vivo. Curr Biol 16: 1515-1523, 2006.

60. Tamir S, Rotem-Bamberger S, Katz C, Morcos F, Hailey KL, Zuris JA, Wang C, Conlan AR, Lipper CH, Paddock ML, et al: Integrated strategy reveals the protein interface between cancer targets Bcl-2 and NAF-1. Proc Natl Acad Sci USA 111: 5177-5182, 2014.
61. Murakami R, Matsumura N, Mandai M, Yoshihara K, Tanabe H, Nakai H, Yamanoi K, Abiko K, Yoshioka Y, Hamanishi J, et al: Establishment of a Novel Histopathological Classification of High-Grade Serous Ovarian Carcinoma Correlated with Prognostically Distinct Gene Expression Subtypes. Am J Pathol 186: 1103-1113, 2016.

62. Laskin DM, Abubaker AO and Strauss RA: Accuracy of predicting the duration of a surgical operation. J Oral Maxillofac Surg 71: 446-447, 2013.

63. Gabarra-Niecko V, Schaller MD and Dunty JM: FAK regulates biological processes important for the pathogenesis of cancer. Cancer Metastasis Rev 22: 359-374, 2003.

64. Sandilands E, Serrels B, McEwan DG, Morton JP, Macagno JP, McLeod K, Stevens C, Brunton VG, Langdon WY, Vidal M, et al: Autophagic targeting of Src promotes cancer cell survival following reduced FAK signalling. Nat Cell Biol 14: 51-60, 2011.

65. Serrels A, Canel M, Brunton VG and Frame MC: Src/FAK-mediated regulation of E-cadherin as a mechanism for controlling collective cell movement: Insights from in vivo imaging. Cell Adhes Migr 5: 360-365, 2011.

66. Alapati K, Gopinath S, Malla RR, Dasari VR and Rao JS: uPAR and cathepsin B knockdown inhibits radiation-induced PKC integrated integrin signaling to the cytoskeleton of glioma-initiating cells. Int J Oncol 41: 599-610, 2012.

This work is licensed under a Creative Commons

Attribution-NonCommercial-NoDerivatives 4.0 International (CC BY-NC-ND 4.0) License. 